\title{
PENENTUAN UMUR EKONOMIS DUMP TRUCK HD 785-7 DENGAN MENGGUNAKAN METODA BIAYA TAHUNAN RATA-RATA PADA PT. SEMEN PADANG
}

\author{
Riko Ervil ${ }^{1}$ dan Rizki Ananda Putri ${ }^{2}$ \\ ${ }^{1,2}$ SekolahTinggiTeknologiIndustri (STTIND) Padang \\ Rikoervil@sttind.ac.id
}

\begin{abstract}
Abstrak: PT Semen Padang, memiliki peralatan investasi tinggi dan biaya operasi tinggi, terutama dalam penyediaan bahan baku batu kapur, silika, tanah liat dan distribusinya. Objek penelitian ini adalah dump truck HD 785-7 sebagai kendaraan bahan baku yang dioperasikan oleh PT. Semen Padang. Menurut data akumulatif dari Juli hingga Desember 2012 setiap kegagalan kendaraan ini akan menghambat operasi dan biaya sebanyak Rp.700.000.000, -. Tujuan penelitian ini adalah untuk menentukan umur ekonomis dump truck HD 785-7 dengan menggunakan metode biaya rata-rata tahunan. Penelitian ini dilakukan dengan spesifikasi mesin, nilai investasi dump truck, data penggunaan bahan bakar, data pemakaian pelumas, data penggantian suku cadang, data waktu operasional, data layanan dump truck. Berdasarkan semua data, kita dapat mengetahui kehidupan ekonomi dump truck HD $785-7$ dengan menggunakan metode biaya rata-rata tahunan. Setelah proses perhitungan dan analisis data, kami menyimpulkan bahwa umur ekonomis dump truck HD 785-7 adalah 4 tahun, dari tahun 2011 sebagai tahun pembelian hingga tahun 2014. Oleh karena itu, pada tahun keempat, PT. Semen Padang memiliki 2 pilihan: mengganti truk atau melakukan perawatan.
\end{abstract}

Kata Kunci: Kehidupan Ekonomi, Dump Truck HD 785-7, Biaya Tahunan Rata-rata.

Abstract: PT Semen Padang, a cement company, has equipment high investment and high operating costs, especially in raw material provision limestone, silica, clay and their distribution. The object of this research is dump truck HD 785-7 as a vehicle of raw material operated by PT. Semen Padang. According to accumulative data from July to December 2012 any failure to this vehicle will obstruct operation and cost as much as Rp.700.000.000,- . The purpose of this research is to determine economic life of dump truck HD 785-7 by using average annual cost method. This research conducted by machine specification, investment value of dump truck, fuel usage data, lubricants usage data, spare part replacement data, operational time data, dump truck service data.Based on all data, we can figure out economic life of dump truck HD 785-7 by using average annual cost method. After calculation process and analyzing data, we concluded that economic life of dump truck HD 785-7 was 4 years, from 2011 as the purchasing year to 2014. Therefore, in the fourth year, PT. Semen Padang has 2 options: replacing the truck or do the maintenance.

Key Word: Economic Life, Dump Truck HD 785-7, Average Annual Cost 


\section{PENDAHULUAN}

Sejalan dengan perkembangan zaman dan teknologi maka semakin pesat pula persaingan dalam dunia bisnis. Sehingga semua pihak berusaha mendapatkan teknologi yang sesuai dengan biaya yang serendah mungkin. Untuk mendapatkan biaya terendah adalah dengan menggunakan salah satu cara yaitu dengan mengendalikan investasi, baik investasi awal maupun investasi lanjutan yang antara lain berupa pengendalian peralatan.

PT. Semen Padang yang bergerak dalam bidang pembuatan semen, memiliki peralatan-peralatan yang memerlukan investasi awal dan biaya operasi cukup besar. Keuntungan perusahaan sangat besar kaitannya dengan biaya produksi, hingga peningkatan keuntungan sejalan dengan penurunan ongkos produksi. Penurunan ongkos produksi dapat dilaksanakan antara lain dengan cara menurunkan biaya operasi mesin dan peralatan serendah mungkin (riko ervil, 2016). Salah satunya adalah dengan melaksanakan penggantian mesin tepat pada waktunya.

Khususnya dalam penyediaan bahan baku seperti batu gamping, silica, dan clay, tentunya dibutuhkan alat berat yang akan memuat dan mengangkut materialmaterial tersebut.

Objek penelitian adalah dump truck $H D$ 785-7 yang dioperasikan diarea pertambangan PT. Semen Padang sebagai alat angkut material (batu gamping) yang sebelumnya telah diledakan untuk selanjutnya dibawa ke crusher.

Kerusakan dump truck HD 785-7 di area penambangan ini dapat mengganggu jalannya proses pengangkutan batu gamping itu sendiri dan kerugian akibat kerusakan itu sendiri pada tahun 2012 terhitung mulai bulan juli hingga desember mencapai Rp. 700.000.000,- . Dapat dilihat pada tabel 1.2 berikut :

Tabel 1.Data Kerusakan Dump Truck HD 785-7

\begin{tabular}{|c|c|c|c|c|c|}
\hline Hari & Tanggal & $\begin{array}{c}\text { Statu } \\
\text { s }\end{array}$ & Jenis Kegiatan & $\begin{array}{c}\text { Status } \\
\text { Kegiata } \\
n\end{array}$ & Kegiatan \\
\hline Selasa & 10 Juli 2012 & Stop & $\mathrm{GOH}$ & $\begin{array}{c}\text { Breakd } \\
\text { own }\end{array}$ & $\begin{array}{c}\text { Rear Brake } \\
\text { Problem }\end{array}$ \\
\hline Senin & 16 Juli 2012 & Stop & $\mathrm{OH}$ & $\begin{array}{c}\text { Breakd } \\
\text { own }\end{array}$ & $\begin{array}{c}\text { Rear Brake } \\
\text { Overhaul }\end{array}$ \\
\hline Selasa & 17 Juli 2012 & Stop & $\mathrm{OH}$ & $\begin{array}{c}\text { Breakd } \\
\text { own }\end{array}$ & $\begin{array}{c}\text { Rear Brake } \\
\text { Overhaul }\end{array}$ \\
\hline Rabu & 18 Juli 2012 & Stop & $\mathrm{OH}$ & $\begin{array}{c}\text { Breakd } \\
\text { own }\end{array}$ & $\begin{array}{c}\text { Rear Brake } \\
\text { Overhaul }\end{array}$ \\
\hline Minggu & 22 Juli 2012 & Stop & $\mathrm{OH}$ & $\begin{array}{c}\text { Breakd } \\
\text { own }\end{array}$ & $\begin{array}{c}\text { Overhaul } \\
\text { rear brake }\end{array}$ \\
\hline Minggu & 08 Juli 2012 & Stop & $\begin{array}{c}\text { Daily } \\
\text { Inspection }\end{array}$ & $\begin{array}{c}\text { Trouble } \\
\text { shootin } \\
\mathrm{g}\end{array}$ & $\begin{array}{c}\text { hose cooling } \\
\text { brake }(\mathrm{LH}) \\
\text { belakang } \\
\text { bocor }\end{array}$ \\
\hline Selasa & 10 Juli 2012 & Stop & $\begin{array}{c}\text { Daily } \\
\text { Inspection }\end{array}$ & $\begin{array}{c}\text { Trouble } \\
\text { shootin } \\
\mathrm{g}\end{array}$ & $\begin{array}{l}\text { Transmission } \\
\text { filter caution }\end{array}$ \\
\hline Rabu & $\begin{array}{l}15 \text { Agustus } \\
2012\end{array}$ & Stop & $\begin{array}{c}\text { Troubleshooti } \\
\text { ng }\end{array}$ & $\begin{array}{c}\text { Trouble } \\
\text { shootin } \\
\mathrm{g}\end{array}$ & $\begin{array}{l}\text { perbaikan } \\
\text { brake }\end{array}$ \\
\hline Selasa & $\begin{array}{l}21 \text { Agustus } \\
2012\end{array}$ & Stop & $\begin{array}{c}\text { Troubleshooti } \\
\text { ng }\end{array}$ & $\begin{array}{c}\text { Trouble } \\
\text { shootin } \\
\mathrm{g}\end{array}$ & $\begin{array}{c}\text { tidak mau } \\
\text { maju dan } \\
\text { mundur }\end{array}$ \\
\hline Jumat & $\begin{array}{l}31 \text { Agustus } \\
2012\end{array}$ & $\begin{array}{c}\text { STO } \\
\mathrm{P}\end{array}$ & $\begin{array}{c}\text { Troubleshooti } \\
\text { ng }\end{array}$ & $\begin{array}{c}\text { Trouble } \\
\text { shootin } \\
\mathrm{g}\end{array}$ & $\begin{array}{c}\text { tidak mau } \\
\text { start }\end{array}$ \\
\hline Selasa & \begin{tabular}{|c|}
04 \\
September \\
2012 \\
\end{tabular} & $\begin{array}{l}\text { Stan } \\
\text { dby }\end{array}$ & $\begin{array}{c}\text { Troubleshooti } \\
\text { ng }\end{array}$ & $\begin{array}{c}\text { Breakd } \\
\text { own }\end{array}$ & $\begin{array}{c}\text { Hose Front } \\
\text { Brake RH } \\
\text { bocor }\end{array}$ \\
\hline Jumat & $\begin{array}{c}28 \text { Desember } \\
2012\end{array}$ & Stop & $\begin{array}{c}\text { Troubleshooti } \\
\text { ng }\end{array}$ & $\begin{array}{c}\text { Trouble } \\
\text { shootin } \\
\mathrm{g}\end{array}$ & $\begin{array}{c}\text { Tidak mau } \\
\text { start }\end{array}$ \\
\hline Sabtu & $\begin{array}{c}29 \text { Desember } \\
2012\end{array}$ & Stop & $\begin{array}{c}\text { Troubleshooti } \\
\text { ng }\end{array}$ & $\begin{array}{c}\text { Trouble } \\
\text { shootin } \\
\mathrm{g}\end{array}$ & $\begin{array}{c}\text { Tidak mau } \\
\text { start }\end{array}$ \\
\hline Jumat & $\begin{array}{c}28 \text { Desember } \\
2012\end{array}$ & Stop & $\begin{array}{c}\text { Troubleshooti } \\
\text { ng }\end{array}$ & $\begin{array}{c}\text { Trouble } \\
\text { shootin } \\
\mathrm{g}\end{array}$ & $\begin{array}{l}\text { Hose cooling } \\
\text { brake bocor }\end{array}$ \\
\hline Sabtu & $\begin{array}{c}29 \text { Desember } \\
2012\end{array}$ & Stop & $\begin{array}{c}\text { Troubleshooti } \\
\text { ng }\end{array}$ & $\begin{array}{c}\text { Trouble } \\
\text { shootin } \\
\mathrm{g}\end{array}$ & $\begin{array}{l}\text { Oli transmisi } \\
\text { kurang }\end{array}$ \\
\hline
\end{tabular}

Sumber : Kantor CBM PT. Semen Padang.

\section{METODE PENELITIAN}

Metoda penelitian ini bersifat ex post facto, yaitu data dikumpulkan setelah semua kejadian yang dikumpulkan telah selesai berlangsung. Peneliti dapat melihat sebab-akibat dari suatu fenomena dan menguji hubungan sebab-akibatnya dari data- data yang tersedia.(Nazir, 2009).

Penelitian akan dilaksanakan di PT. Semen Padang berada di Jl. Raya Indarung, Padang 25237, Sumatera Barat. Lokasi pabrik dan kantor pusat PT. Semen Padang terletak di Kelurahan Indarung kecamatan Lubuk Kilangan Kotamadya Padang, Propinsi Sumatera Barat, yang berjarak sekitar $15 \mathrm{~km}$ ke arah timur pusat Kota Padang. Secara geografis lokasi pabrik berada pada ketinggian lebih kurang 200 meter di atas permukaan laut. Sedangkan waktu penelitian dilaksanakan 
pada bulan Juni 2015.

Data yang peneliti butuhkan dalam penelitian ini adalah data sekunder diperoleh dari buku-buku literature atau studi kepustakaan dan data-data/arsip perusahaan. Seperti berikut :

1) Spesifikasi Dump Truck

2) Investasi Dump Truck

3) Data Bahan Bakar

4) Data Pelumas

5) Data Penggantian Suku Cadang

6) Data Jam Operasi

7) Data Jam Perbaikan

Adapun teknik pengolahan data yang dilakukan dalam penelitian ini didasarkan pada umur ekonomis mesin yang perhitungannya dilakukan dengan cara biaya tahunan rata-rata:

1) Menghitung Harga Akhir Mesin

2) Menghitung Capital Recovery

3) Menghitung Biaya Operasi Dump

Truck

4) Menghitung Biaya Downtime

5) Menghitung Biaya Operasi Tahunan

6) Perhitungan Biaya Tahunan Rata-Rata

7) Memilih Total Biaya Tahunan Rata-

Rata

\section{HASIL DAN PEMBAHASAN}

Pengolahan Data Perhitungan Harga Akhir Dump Truck HD 785-7:

Rumus yang berlaku adalah : $\mathrm{F}_{\mathrm{n}}=\mathrm{P}(1-\mathrm{k})^{\mathrm{t}}$. Dengan nilai $\mathrm{k}=2 / \mathrm{n}=2 / 4=0,5$.Dengan penyelesaian sebagai berikut dalam tabel:

Tabel 2. Perhitungan Harga Akhir Dump Truck HD 785-7

\begin{tabular}{|c|c|c|c|c|c|r|}
\hline Tahun & \multicolumn{2}{c|}{ P } & k & t & \multicolumn{2}{|c|}{ Fn } \\
\hline 2011 & $\mathrm{Rp}$ & 10.500 .000 .000 & 0,5 & 1 & $\mathrm{Rp}$ & 5.250 .000 .000 \\
\hline 2012 & $\mathrm{Rp}$ & 10.500 .000 .000 & 0,5 & 2 & $\mathrm{Rp}$ & 2.625 .000 .000 \\
\hline 2013 & $\mathrm{Rp}$ & 10.500 .000 .000 & 0,5 & 3 & $\mathrm{Rp}$ & 1.312 .500 .000 \\
\hline 2014 & $\mathrm{Rp}$ & 10.500 .000 .000 & 0,5 & 4 & $\mathrm{Rp}$ & 656.250 .000 \\
\hline
\end{tabular}

Perhitungan Depresiasi Tahunan (Capital Recovery)

Setelah harga present value $(\mathrm{P})$ dan harga akhir (F) tiap tahun dump truck diperoleh, selanjutnya depresiasi tahunan (CR) ditentukan dengan rumus : $\mathrm{CR}=(\mathrm{P}-$
F) $(\mathrm{A} / \mathrm{P}, \mathrm{i} \%, \mathrm{~N})+\mathrm{F}_{\mathrm{i}}$. Suku bunga yang dipilih disesuaikan dengan suku bunga deposito bank yaitu $\mathrm{i}=7 \%$. Dengan penyelesaian sebagai berikut dalam tabel 3 .

Tabel 3. Perhitungan Depresiasi Tahunan Dump Truck HD 785-7

\begin{tabular}{|c|c|c|c|c|c|c|}
\hline Tahun & $\mathbf{P}$ & $\mathbf{F}$ & $\mathbf{n}$ & $\mathbf{i}$ & $\begin{array}{c}\text { Capital } \\
\text { Recovery } \\
\text { Factor }\end{array}$ & CR \\
\hline 2011 & $\mathrm{Rp} 10.500 .000 .000$ & $\mathrm{Rp} \mathrm{5.250.000.000}$ & 1 & $7 \%$ & 1,0700 & $\begin{array}{c}\mathrm{Rp} \\
5.985 .000 .000\end{array}$ \\
\hline 2012 & $\mathrm{Rp} 10.500 .000 .000$ & $\mathrm{Rp} 2.625 .000 .000$ & 2 & $7 \%$ & 0,5531 & $\begin{array}{c}\mathrm{Rp} \\
4.539 .412 .500\end{array}$ \\
\hline 2013 & $\mathrm{Rp} 10.500 .000 .000$ & $\mathrm{Rp} 1.312 .500 .000$ & 3 & $7 \%$ & 0,3811 & $\begin{array}{c}\mathrm{Rp} \\
3.593 .231 .250\end{array}$ \\
\hline 2014 & $\mathrm{Rp} 10.500 .000 .000$ & $\mathrm{Rp} 656.250 .000$ & 4 & $7 \%$ & 0,2952 & $\begin{array}{c}\mathrm{Rp} \\
2.951 .812 .500\end{array}$ \\
\hline
\end{tabular}

Menghitung Biaya Downtime Dump Truck HD 785-7

Sebelum menghitung rata-rata downtime harus dihitung downtime mesin setiap tahunnya kemudian hitung rata-rata down time dengan menggunakan persamaan : $\mathbf{r d}=\sum \mathbf{d} / \mathbf{n}$. Sehingga :

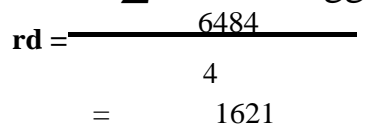

Penyelesaian dan hasil perhitungan dapat dilihat pada tabel 4 berikut :

Tabel 4. Perhitungan Rata-Rata Downtime setiap

\begin{tabular}{|c|c|c|}
\hline \multicolumn{3}{|c|}{ tahun. } \\
$\begin{array}{c}\text { Pam } \\
\text { Perbaikan }\end{array}$ & $\begin{array}{c}\text { Rata-Rata } \\
\text { Downtime } \\
\text { setiap tahun (rd) }\end{array}$ \\
\hline 2011 & 464 & \\
\hline 2012 & 1574 & 1621 \\
2013 & 708 & \\
\hline 2014 & 3738 & \\
\hline Jumlah & 6484 & \\
\hline \multicolumn{2}{|c|}{ Setelah didapatkan rata-rata dari }
\end{tabular}
downtime mesin, selanjutnya dapat dihitung biaya downtime dengan menggunakan persamaan :

Berikut ini adalah hasil perhitungan biaya downtime :

Tabel 5. Perhitungan Biaya Downtime Dump Truck 
HD 785-7.

\begin{tabular}{|c|c|c|c|c|c|c|c|c|}
\hline Tahu & \begin{tabular}{|c} 
Jam \\
Perbaikan \\
Per \\
Tahun
\end{tabular} & $\begin{array}{c}\text { Jam } \\
\text { Kerja } \\
\text { Per } \\
\text { Tahun }\end{array}$ & $\begin{array}{c}\text { Biaya } \\
\text { Mintenance } \\
\text { Per } \\
\text { Tahun }\end{array}$ & $\begin{array}{c}\text { Capital } \\
\text { Recovery }\end{array}$ & $\begin{array}{c}\text { MAR } \\
\mathrm{R}\end{array}$ & $\begin{array}{l}\text { Rata- } \\
\text { Rata } \\
\text { Downtim } \\
\text { setiap } \\
\text { tahun } \\
\text { (rd) }\end{array}$ & & $\begin{array}{l}\text { Biaya Down } \\
\text { Time } \\
\text { Per Tahun }\end{array}$ \\
\hline 2011 & 464 & 5840 & $\begin{array}{c}\operatorname{Rp} 145,259, \\
717\end{array}$ & $\operatorname{Rp} \begin{array}{c}5,985,000 \\
000\end{array}$ & & & $\mathrm{Rp}$ & $116,287,320$ \\
\hline $\begin{array}{l}2012 \\
2013\end{array}$ & $\begin{array}{c}3738 \\
708\end{array}$ & $\begin{array}{l}5840 \\
5840\end{array}$ & $\begin{array}{c}\operatorname{Rp} 5562,304, \\
\operatorname{Rp} \\
823 \\
472,014, \\
062\end{array}$ & \begin{tabular}{c|c}
$\operatorname{Rp}$ & $4,539,412$, \\
$\operatorname{Rp}$ & 500 \\
& $3,593,231$, \\
& 250
\end{tabular} & $7 \%$ & 1621 & $\begin{array}{l}\mathrm{Rp} \\
\mathrm{Rp}\end{array}$ & $\begin{array}{l}88,199,852 \\
69,815,745\end{array}$ \\
\hline 2014 & 1574 & 5840 & \begin{tabular}{|c|c|}
$\operatorname{Rp} 285,614$, \\
343
\end{tabular} & \begin{tabular}{c|c}
$\operatorname{Rp}$ & $2,951,812$, \\
500
\end{tabular} & & & $\mathbb{R p}$ & $57,353,110$ \\
\hline
\end{tabular}

Menghitung Biaya Operasi Tahunan RataRata

Untuk menghitung biaya operasi tahunan rata-rata, maka dapat dihitung dengan rumus berikut :

Present Worth Biaya Operasi = Biaya Operasi per Tahun $\mathrm{x}$ Present Worth Factor $(\mathrm{P} / \mathrm{F}, 7 \%, \mathrm{n})$

$\sum$ Present Value Biaya Operasi $=\sum$ Present Value Biaya Operasi + Present Value Biaya Operasi Biaya Operasi

Tahunan Rata-Rata $=\sum$ Present Value Biaya Operasi $\mathrm{x}$ Capital Recovery (A/P,7\%,n)

Tabel 6. Perhitungan Biaya Operasi Tahunan RataRata

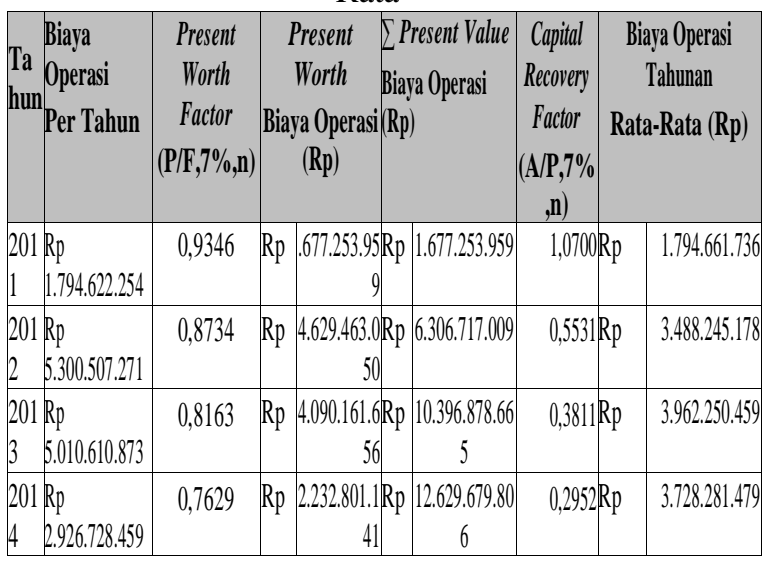

Perhitungan Biaya Tahunan Rata-Rata

Pada perhitungan biaya tahunan ratarata ini dapat diketahui umur ekonomis suatu mesin yang diperoleh jika total biaya tahunan rata-rata dump truck $H D$ 785-7 minimum. Jika tidak didapatkan total biaya tahunan rata-rata minimum, maka langkah yang dilakukan adalah dengan melakukan peramalan.
Untuk menghitung total biaya tahunan rata-rata dapat dilakukan dengan cara menjumlahkan semua elemen biaya diatas seperti dalam rumus berikut : Total BiayaTahunan Rata-rata

= CR (Capital Recovery) + biaya downtime ratarata + biaya operasi tahunan rata-rata.

Sehingga total biaya tahunan rata-rata dapat dilihat dalam tabel 7 berikut :

Tabel 7. Total Biaya Tahunan Rata-Rata

\begin{tabular}{|c|c|c|c|c|c|}
\hline Tahun & $\begin{array}{c}\text { Biaya Operasi } \\
\text { Rata-Rata }\end{array}$ & $\begin{array}{c}\text { Biaya Downtime } \\
\text { Rata-Rata) }\end{array}$ & \multicolumn{2}{|c|}{ Capital Recovery } & $\begin{array}{l}\text { Total Biaya } \\
\text { Rata-Rata }\end{array}$ \\
\hline $2011 \mathrm{Rp}$ & \begin{tabular}{|l|l|} 
& $1,794,661,736 \mathrm{R}$ \\
\end{tabular} & \begin{tabular}{l|l}
$\mathrm{Rp}$ & $116,289,879$ \\
\end{tabular} & & $5,985,000,000 \mathrm{Rp}$ & \begin{tabular}{|l|l}
$7,895,951,614$ \\
\end{tabular} \\
\hline 2012Rp & 3,488 & 102,7 & & $0 \mathrm{Rp}$ & \\
\hline 2013Rp & $3,962,250,459 \mathrm{R}$ & $92,495,4$ & & $3,593,231,250 \mathrm{Rp}$ & 7,647,977,146 \\
\hline $2014 R p$ & $3,728,281,479 R$ & $84,563,335$ & & $2,951,812,500 \mathrm{Rp}$ & \begin{tabular}{|l|l|}
$p$ & $6,764,657,313$ \\
\end{tabular} \\
\hline
\end{tabular}

Memilih Total Biaya Tahunan Rata-Rata

Umur ekonomis mesin dapat ditentukan melihat hasil dari perhitungan total biaya tahunan rata-rata diatas dengan ketentuan total biaya rata-rata minimum yang dijadikan tahun ekonomis atau umur ekonomis dari Dump Truck HD 785-7. Dari perhitungan diatas maka hasil telah dapat ditentukan dimana tahun ke empat menjadi tahun ekonomis atau umur ekonomis Dump Truck HD 785-7 dengan total minimum dari total biaya tahun-tahun sebelumnya.

\section{KESIMPULAN}

Setelah melakukan perhitungan dan analisis terhadap permasalahan, maka dapat diambil suatu kesimpulan yaitu, diketahui umur ekonomis dump truck $H D$ 785- 7 sebagai alat angkut batu gamping adalah 4 tahun dimulai dari pembelian tahun 2011 sampai tahun ke-4 (2014).

Agar hasil penelitian ini dapat berguna dikemudian hari bagi PT. Semen Padang pada umumnya, maka diberikan saransaran sebagai berikut : Sebaiknya apabila umur ekonomis dump truck HD 785-7 telah lewat dari waktu perhitungan, perusahaan disarankan untuk mengganti alat angkut tersebut. Karena semakin lama umur dump truck HD 785-7 maka akan kehilangan kesempatan yang lebih besar 


\section{DAFTAR PUSTAKA}

DeGarmo. E. Paul. Sullivan G. William. Bontadelli A. James. Wicks M. Elin. Ekonomi Teknik (Terjemahan). Edisi Kesepuluh. Jilid Pertama. PT. Prenhallindo. Jakarta. 1999.

Eugene L.Grant. W. Grant Ireson and Richard S. Leavenworth. Dasar-dasar Ekonomi Teknik (Terjemahan). Edisi Ketiga. Jilid Pertama. PT. RinekaCipta. Jakarta. 1996.

Pujawan I Nyoman. Ekonomi Teknik. Edisi Kedua. PT. GunaWijaya. Surabaya. 2009. Rochman hadi. Alat-Alat Berat dan Penggunaannya.PT. Pelita Kasih. Jakarta. 1989. TENOO 164-00. Operational And Maintanance Dump Truck HD 785-7. Komatsu.Japan. 2006.

Vincent. Gasperz.ManajemenProductivitas Total, StrategiPeningkatanBisnis Global.PT. GramediaPustakaUtama. Jakarta.1998.

riko ervil. (2016). Perbandingan Nilai Overall Equipment Effectiveness (Oee) Mesin Packer Lama Dan Mesin Packer Baru Pada Packing Plant Indarung (Ppi) Pt. Semen Padang. Saint Dan Teknologi STTIND Padang, 16(2). 